\title{
Intramuscular ziprasidone reduced symptoms and was well tolerated in acute psychosis
}

Brook S, Lucey JV,Gunn KP, for the Ziprasidone IM Study Group. Intramuscular ziprasidone compared with intramuscular haloperidol in the treatment of acute psychosis. J Clin Psychiatry 2000 Dec;61:933-41.

QUESTIONS: In patients admitted to hospital with acute psychotic agitation, how efficacious and tolerable is intramuscular (IM) ziprasidone compared with IM haloperidol, both followed by oral treatment?

\section{Design}

Randomised (unclear allocation concealment*), unblinded*, controlled trial with 7 days of follow up.

Source of funding: Pfizer Inc.

Setting

19 centres in 7 countries.

For correspondence: Dr S Brook, Research Unit, Sterkfontain Hospital, Krugersdorp, South Africa. simunye@jhb.lia.net.

\section{Patients}

132 patients (mean age 34 y, 93\% men) recently admitted to hospital with acute psychosis as defined by $D S M-I I I-R$. Exclusion criteria included acute psychosis related to substance abuse or of organic origin.

Table 1 Mean change from baseline (SD) in scale scores comparing ziprasidone and haloperidol, intramuscularly (IM) and orally, in acute psychosist

\begin{tabular}{llll} 
Outcome up to day 3 & IM ziprasidone & IM haloperidol & p Value \\
BPRS total & $-6.24(8.30)$ & $-3.18(6.55)$ & 0.02 \\
\hline BPRS agitation items & $-1.93(3.41)$ & $-0.80(2.81)$ & 0.02 \\
\hline CGI-S & $-0.49(0.68)$ & $-0.15(0.53)$ & 0.002 \\
\hline Outcome at day 7 & Oral ziprasidone & Oral haloperidol & p Value \\
BPRS total & $-8.76(11.62)$ & $-5.83(9.50)$ & 0.09 \\
\hline BPRS agitation items & $-2.09(4.41)$ & $1.59(3.61)$ & 0.19 \\
\hline CGI-S & $-0.89(1.23)$ & $-0.38(1.17)$ & 0.03 \\
\hline
\end{tabular}

tBPRS=Brief Psychiatric Rating Scale, CGI-S=Clinical Global Impressions Severity Scale.

Table 2 Intramuscular (IM) ziprasidone v IM haloperidol in acute psychosis

\begin{tabular}{lllll} 
Outcome up to day 3 & $\begin{array}{l}\text { IM } \\
\text { ziprasidone }\end{array}$ & $\begin{array}{l}\text { IM } \\
\text { haloperidol }\end{array}$ & $\begin{array}{l}\text { RRR } \\
(95 \% \text { Cl) }\end{array}$ & $\begin{array}{l}\text { NNT } \\
\text { (CI) }\end{array}$ \\
\hline Adverse events & $31 \%$ & $50 \%$ & $38 \%(3$ to 59$)$ & 6 (3 to 92) \\
\hline
\end{tabular}

‡Abbreviations defined in glossary. RRR, NNT, and Cl calculated from data in article.

\section{Intervention}

90 patients received up to 3 days of IM ziprasidone (initial dose of $10 \mathrm{mg}$ followed by IM doses of 5-20 mg every $4-6 \mathrm{~h}$ [maximum daily dose $80 \mathrm{mg}$ ] if needed, then $80-200 \mathrm{mg} / \mathrm{d}$ orally to day 7 ) while 42 received IM haloperidol (initial dose of 2.5-10 $\mathrm{mg}$ followed by 2.5-10 mg IM every 4-6 h [maximum daily dose $40 \mathrm{mg}$ ] if needed, then by $10-80 \mathrm{mg} / \mathrm{d}$ orally).

\section{Main outcome measures}

Scores on the Brief Psychiatric Rating Scale (BPRS) total, BPRS agitation items, and Clinical Global Impressions severity (CGI-S) scale, and adverse effects.

\section{Main results}

Between 93\% and 100\% of patients were included in the analyses. Mean reductions from baseline in BPRS total, BPRS agitation items, and CGI-S scores were greater with IM ziprasidone than with IM haloperidol (table 1). Further reductions from baseline were seen after the transition from IM to oral treatment but a statistical difference between treatment groups was seen only for the change in CGI-S scores (table 1). Fewer patients reported adverse effects with IM ziprasidone than with IM haloperidol (table 2).

\section{Conclusions}

In patients with acute psychosis, intramuscular (IM) ziprasidone reduced symptoms and was well tolerated compared with IM haloperidol.

*See glossary.

\section{COMMENTARY}

In treating acute psychosis, clinicians are sometimes required to use antipsychotics in an IM formulation. Haloperidol has come to represent the 'gold standard' for conventional antipsychotics in this respect. Its extrapyramidal side effects in particular, however, have posed problems in the clinical setting, and clinicians have been anxious to have a short acting IM formulation of an 'atypical' antipsychotic.

This study by Brook $e t$ al provides a comparison of IM ziprasidone and haloperidol in acutely psychotic patients where IM treatment was seen as warranted, at least in the initial stages. The authors point out that the design "mimicked real life clinical practice", that is, acute treatment over a 1 week interval, during which the IM medications were replaced by their oral counterparts within 3 days. While concomitant medications were allowed, including a benzodiazepine, details are not provided as to how they were used and to what extent.

Clinicians must distinguish between behavioural control and antipsychotic efficacy. The data here support ziprasidone's superiority on measures of global outcome, as well as a score for agitation. It would be interesting to have a comparison focused on psychotic symptoms specifically.

The finding that problems in the QTc interval were not encountered will be reassuring to clinicians, given the reported link between ziprasidone and QTc prolongation and the recent publicity this topic has received.

The conclusions of this study stand, but must be viewed in the context of several caveats. In the treatment of acute psychosis, administering haloperidol in combination with a benzodiazepine from the outset of treatment has become routine; the present study did not exclude benzodiazepine use but it did not mirror actual clinical practice in this respect. The authors rightfully point out that the haloperidol doses are in line with what can be seen in clinical practice, but this is not to say that these doses are necessarily correct. Indeed, more recent evidence would suggest that the doses used were too high. ${ }^{2}$ This touches upon the final point, which relates to outcome measures. IM ziprasidone was found in this study to be superior to haloperidol in terms of tolerability as well as measures of agitation and global outcome. Each of these, though, could be negatively influenced by excessively high doses of haloperidol.

Gary Remington, MD, PhD, $\operatorname{FRCP}(\mathrm{C})$ Centre for Addiction and Mental Health Toronto, Ontario, Canada

1 Reilly JG, Ayis SA, Ferrier IN, et al. QTc-interval abnormalities and psychotropic drug therapy in psychiatric patients. Lancet 2000;355:1048-52.

2 Bollini P, Pampallona S, Orza MJ, et al. Antipsychotic drugs: is more worse? A meta-analysis of the published randomized control trials. Psychol Med 1994;24:307-16. 